\title{
Correlative Study between ADC Value and Grading of Bladder Carcinoma
}

\author{
HEBA AZZAM, M.D. \\ The Department of Diagnostic and Interventional Radiology, Faculty of Medicine, Cairo University
}

\begin{abstract}
Background: Studying urinary bladder carcinoma is of great importance as it is one of the most common urological malignancies. Accurate pre-operative assessment of disease characteristics and prognosis would be of great help in the diagnosis and treatment planning of bladder cancer.

Aim of Study: The aim of this study is to evaluate the role of the Apparent Diffusion Coefficient (ADC) value in detecting the grading of urinary bladder cancer prior to management.

Patients and Methods: Prospective study of 108 patients with mean age of $60.81 \pm 12.24$, diagnosed with proven bladder carcinoma. Two radiologists prospectively assessed the morphological and qualitative descriptors of the included carcinomas (restricted diffusion) and quantitative analysis of the ADC maps. The mean ADC value of the bladder lesions was calculated and correlated with the pathological grade according which was established by means of an open or a core needle biopsy (considered as the standard reference).

Results: There was significant difference between the mean ADC value of tumors of grade I and III ( $p=0.000)$; and between grade I and II ( $p=0.00)$ with slight less significant difference between grade II and III $(p=0.022)$. High ADC values were associated with low grade tumors.

Conclusion: DWI is a contrast-free modality that allows for both morphological and quantitative analysis. ADC value is a good discriminator between low and high grade tumors and hence predictor of the histological grade of bladder tumors and prognosis.
\end{abstract}

Key Words: Diffusion - ADC value - Urinary bladder cancer - Grade and magnetic resonance imaging.

\section{Introduction}

URINARY bladder cancer is the 9 th most frequent tumor and 13 th cause of cancer related death all over the world. It has been noted that urinary bladder cancer detection is three to four times more common in males than in females [1].

Correspondence to: Dr. Heba Azzam,

E-Mail: heba.m.azzam@gmail.com
Recently, Magnetic Resonance Imaging (MRI) is considered the technique of choice in the preoperative assessment of many tumors by providing multi-planar images, the new addition of functional techniques, higher soft tissue characterization, higher accuracy of staging estimation and accurate detection of the extent of a disease, avoiding the possible effects of radiation associated with the use of CT [2]

In addition diffusion weighted MRI doesn't require contrast media with short exam duration yet it gives valuable information about the biologic characteristics of tissue giving unique data regarding the cellularity and the status of molecular content of water [3].

The ADC is a q value that can be quantified measuring signal attenuation being influenced by microscopic motion, including molecular diffusion of water as well as blood microcirculation [4]

Qualitative and quantitative assessment by DWMRI can detect the nature of the tissues (benign or malignant) and to determine the grade of malignancy and divide bladder tumors into low and high grade tumors [5].

In the current study we evaluated the impact of interpreting Apparent Diffusion Coefficient (ADC) value as a prognostic factor that can predict the grading of invasive urinary bladder cancer before deciding the options of management.

\footnotetext{
List of abbreviations:

ADC : Apparent Diffusion Coefficient

DWI : Diffusion Weighted Images.

MRI : Magnetic Resonance Imaging.

PPV : Positive Predictive Value.

NPV : Negative Predictive Value.

UB : Urinary Bladder.
} 


\section{Patients and Methods}

This study is a prospective analysis, approved by the Ethics Committee at Kasr El-Aini Hospital, the cases were referred from the Urology/ Urosurgery Clinic in Kasr El-Aini Hospital in the period from March 2015 till May 2018. Tumor grading was established by means of transurethral cystoscopic biopsy (considered as the standard reference).

\section{Patients:}

It included 108 patients who underwent non contrast MRI scanning including diffusion weighted sequences.

\section{Inclusion criteria:}

Patients proved to have urinary bladder cancers that require further advanced pathological analysis for grading.

\section{Exclusion criteria:}

- Cases that received neoadjuvant chemotherapy.

- Cases that lacked pathological confirmation.

- Cases proved to be benign.

- Solid masses less than $1 \mathrm{~cm}$ (The ADC value could not be evaluated).

\section{Methods:}

\section{MR imaging:}

MRI was performed using a $1.5 \mathrm{~T}$ magnet scanner (GyroscanIntera; Philips Medical Systems, Best, the Netherlands) equipped with a radiofrequency coil (Quadrature Body Coil; Philips Medical Systems). All the patients were imaged in the supine position, Total study time ranged from 30 to 45 minutes. No sedation was used.

\section{Patient preparations:}

Patients were instructed to start drinking water and prohibit urinatition 1 hour before the MRI examination to moderately distend the bladder. In patients with a urethral catheter, $250-400 \mathrm{ml}$ of sterile saline was used to distend the bladder.

\section{MRI imaging protocol:}

A- Cases were examined first by non contrast sequences: Axial T 1 weighted turbo spin echo images, axial, sagittal and coronal T2 weighted turbo spin echo images were obtained (repetition time/echo time, 2250-3500/90-100; bandwidth, 20-83kHz; matrix, 256 X 256; section thickness, 4-6mm; intersection gap, 1-2mm; field of view, $2 \mathrm{~cm})$.
B- Diffusion-weighted images: They were performed using a "Echo-Planar Imaging" (EPI) sequence with following parameters: $\mathrm{TR} / \mathrm{TE}=$ $5000 / 77 \mathrm{msec}$; slice thickness $=5 \mathrm{~mm}$ and $1 \mathrm{~mm}$ interslice gap; matrix $=256 \times 256$, b-values $(0$, $850,1000,1500 \mathrm{~s} / \mathrm{mm}^{2}$ ); and the diffusion image was supplied from "Spectral Adiabatic Inversion Recovery" (SPAIR) MR sequence. Respiratory triggering was used for better resolution.

Post processing and image analysis:

Qualitative and quantitative analysis of the examined lesions were done as follows:

I- Qualitative analysis: Restricted diffusion was determined by visualization of abnormal bright signal intensity that became enhanced with increasing $\mathrm{b}$ values $(0 \rightarrow 850 \rightarrow 1000 \rightarrow 1500)$ at "Diffusion Weighted" (DW) images. The ADC map presented intermediate/low Signal Intensity (SI) that corresponded to the abnormality.

II- Quantitative analysis: The ADC values were measured manually by applying ROI at areas of bright SI on DW images and intermediate/low SI on ADC maps, aiming to cover as much as possible of the lesion, avoiding cystic/necrotic areas.

\section{Statistical analysis:}

Data were coded and entered using the statistical package SPSS (Statistical Package for the Social Sciences) version 24. Data was summarized using mean, standard deviation, median, minimum and maximum in quantitative data and using frequency (count) and relative frequency (percentage) for categorical data. Comparisons between quantitative variables were done using the chi-square and Fisher's exact tests (6). ROC curve was constructed with area under curve analysis performed to detect best cutoff value of ADC for detection of high grade tumors.

$p$-values less than 0.05 were considered as statistically significant.

\section{Results}

One hundred and eight patients were included in this study, $81(75 \%)$ males and $27(25 \%)$ females, their age ranged from 17 to 79 years (mean age $60.81 \pm 12.24$ ).

The histopathological diagnosis of the patients was: $51(47.2 \%)$ had urothelial UB cancer, 27 $(25 \%)$ urothelial + squamous cell carcinoma, 15 (13.9\%) squamous cell carcinoma, 9 (8.3\%) adenocarcinoma and $6(5.6 \%)$ rare forms (rhabdomyosarcoma and leiomyosarcoma). 
The number of lesions was single in $87(80.6 \%)$, double in $15(13.9 \%)$ and multiple in $6(5.6 \%)$ with circumferential thickening in 60 (55.6), endophytic mass in 21 (19.4\%), enxophytic mass in 18 $(16.7 \%)$ and mixed in $9(8.3 \%) .9$ lesions $(8.3 \%)$ were grade I, 54 lesions (50\%) were grade II and $45(41.7 \%)$ lesions were grade III (Table 1$)$.

Analysis of the diffusion-weighted images and comparison of the mean ADC value with the pathological grade of the tumor was done.
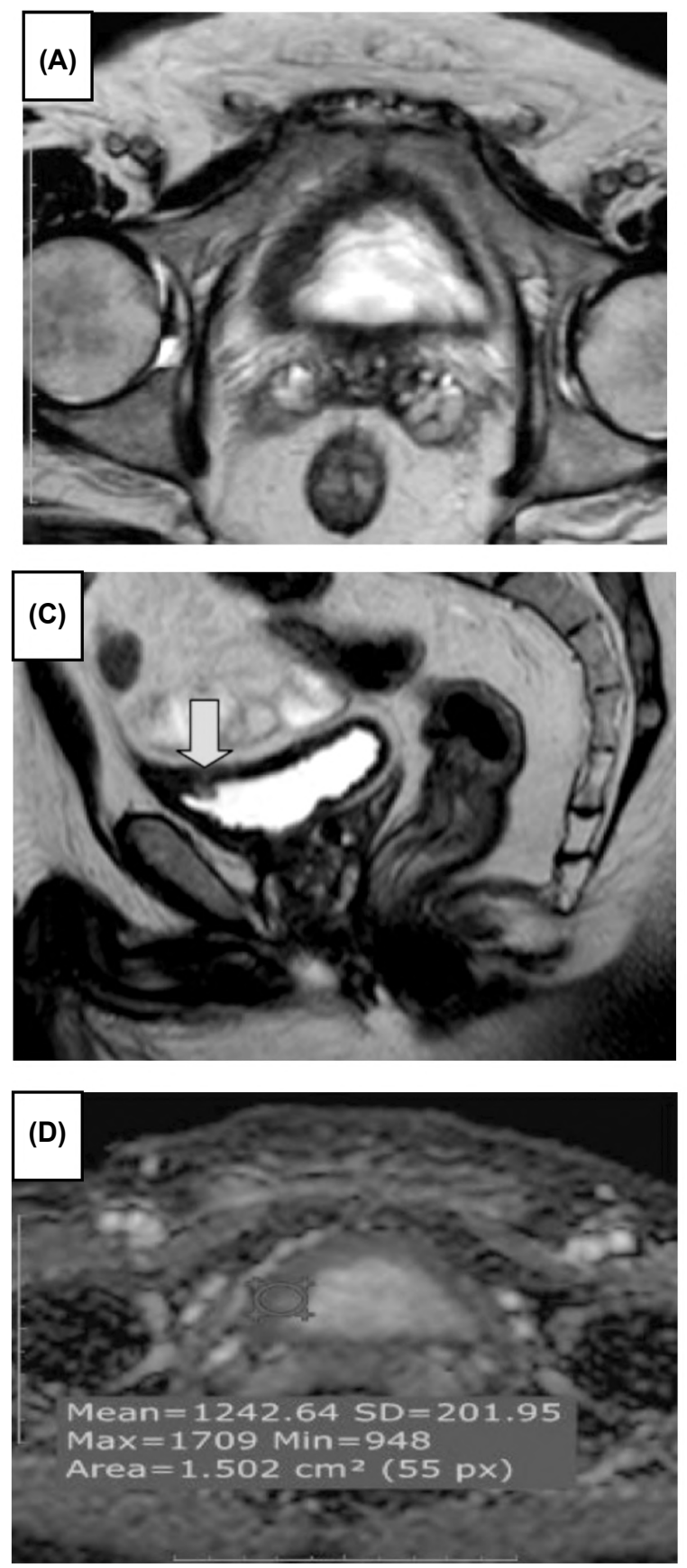

All the included lesions (100\%) showed persistent high signal on DWI with low to intermediate signal on ADC map denoting restricted diffusion Fig. (1).

ADC values ranged from $0_{-3} 48$ to $1.21 \times 10^{-3}$ $\mathrm{mm}^{2} / \mathrm{s}$ (mean $0.81 \pm 0.18 \times 10^{-3} \mathrm{~mm} / \mathrm{s}$ ) Fig. (2).

The mean ADC value of grade $\mathrm{I}_{2}$ grade II and grade III was $1.11 \pm 0.15 \times 10 \mathrm{~mm}_{-3} / \mathrm{s}, 0.83 \pm 0.14$ $\mathrm{X} 10^{-3} \mathrm{~mm} / \mathrm{s}$ and $0.72 \pm 0.14 \times 10^{-3} \mathrm{~mm} / \mathrm{s} \mathrm{respec}-$ tively.
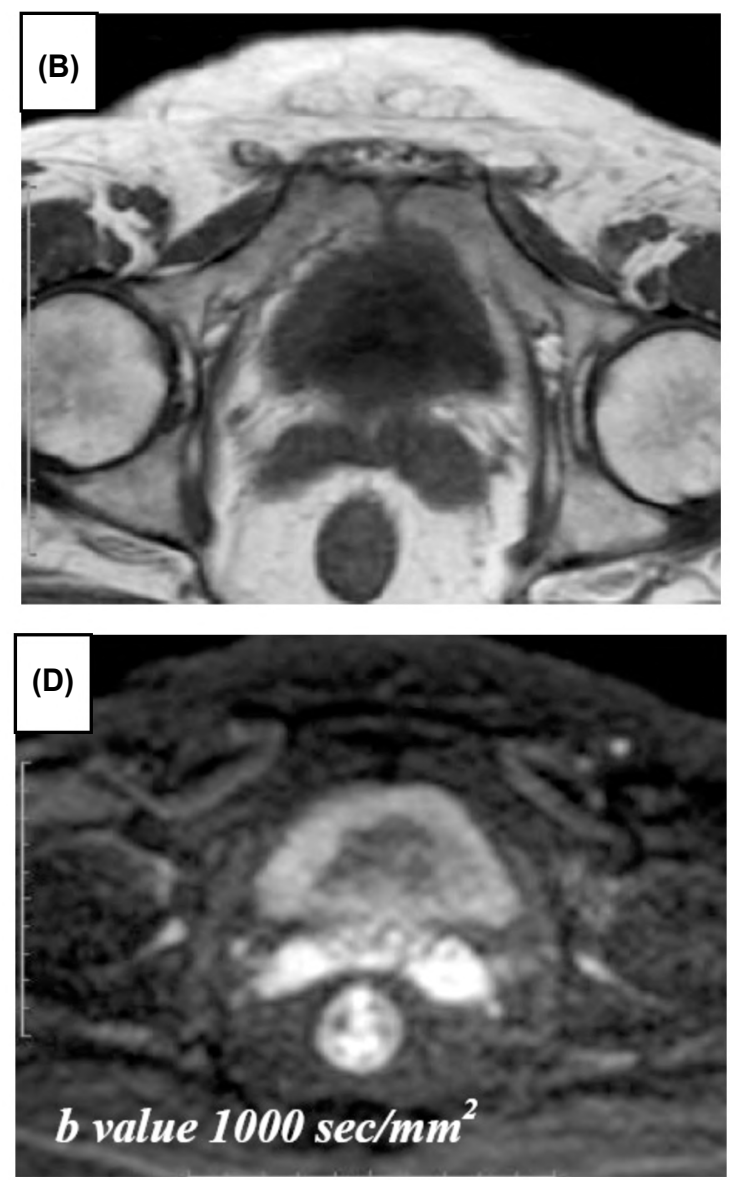

Fig. (1): (A) Axial T2WI, showed circumferential fairly smooth thickening of the urinary bladder wall, more evident on the right mural wall, with maximum thickness measuring $1.72 \mathrm{~cm}$, the muscular layer is seen as an intact (un-interrupted) hypo intense line surrounding the bladder cavity. (B) Axial T1WI, showed intact perivesical fat appeared with no evidence of smudging stranding or infiltration. No evidence of sizable lymphadenopathy was noted. (C) Sagittal T2WI, showed only circumferential mural thickening, with no evidence of interruption of the muscularis propria (low SI line surrounding the high SI of urine) (yellow arrow). (D, E) DWI at $1000 \mathrm{sec} / \mathrm{mm}^{2}$ \& ADC mapping: DWI showed restricted diffusion regarding the thickened mural wall espeçially $y_{2}$ on the right side, ADC value of the tumor was $1.24 \times 10 \mathrm{~mm} / \mathrm{s}$. Histo-pathologically: Tumor was confirmed as grade I urothelial (TCC) carcinoma. 
There was significant difference between the mean ADC value of tumors of grade I and III ( $p=$ $0.000)$; and between grade I and II ( $p=0.000)$ there was slightly less significant difference between grade II and III $(p=0.022)$.

Moreover, statistical analysis of the data revealed that using the ADC value of $0.77 \times 10^{-3}$ $\mathrm{mm}^{2} / \mathrm{s}$ as a cutoff value between high grade tumors (grades II \& III) and low grade tumors (grade I),
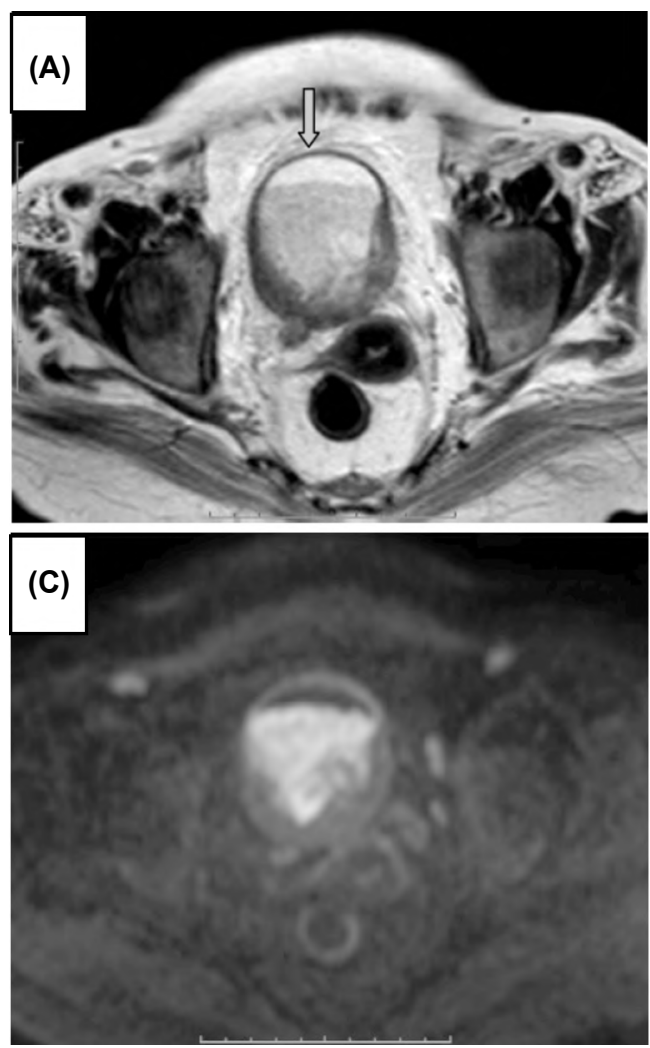

has a sensitivity, specificity, PPV, NPV and accuracy of $60 \%, 71.4 \%, 60 \%, 71.4 \%$ and $66,7 \%$ respectively the mean ADC value of $0.91 \times 10^{-3}$ $\mathrm{mm}^{2} / \mathrm{s}$ showed better statistical indices (sensitivity $93.7 \%$, specificity $100 \%$, PPV $100 \%$, NPV $60 \%$ and accuracy $94.4 \%$ ) and enhanced the performance of the ADC value in the assessment of the tumor celluarity of the bladder carcinoma. Figs. $(3,4)$, (Tables 2,3).
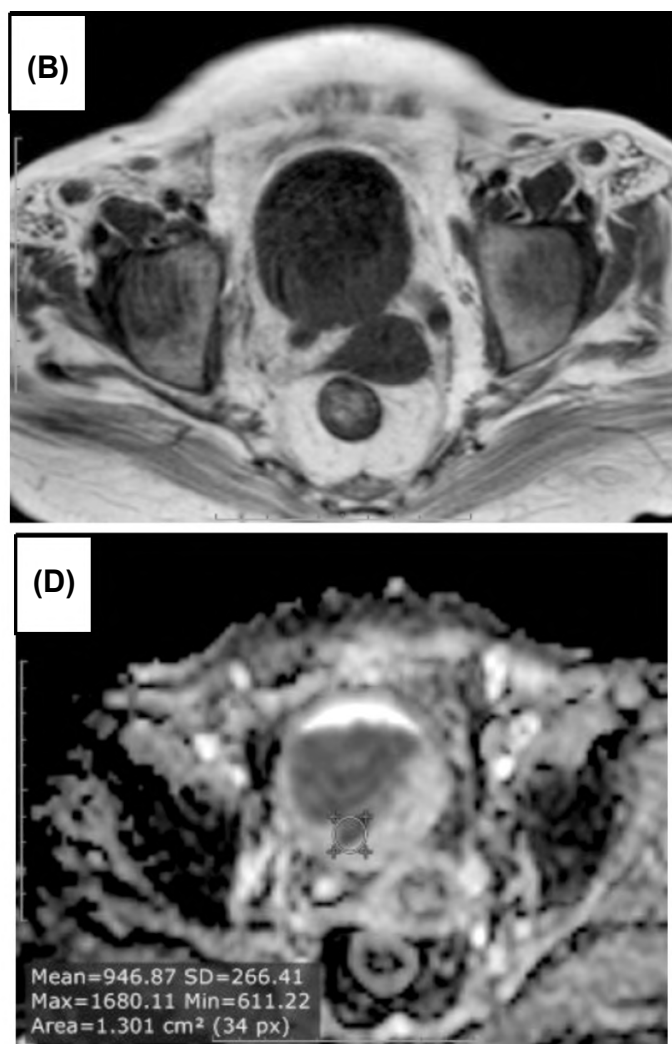

Fig. (2): (A, B) Axial T2WI \& T1WI showing; right and left postero-lateral mural wall thickening involving the whole thickness of the muscularis propria (between 3 O'clock and 9 O'clock), it is seen involving both uretro-vesical junctions as well. The anterior bladder wall is seen spared (where the muscularis propria appears as an uninterrupted low SI line (yellow arrow) on T2WI). On T1WI the perivescal fat planes can be clearly seen to be spared and devoid of any signs of invasion by the tumor. (C, D) DWI at b value of $1000 \mathrm{sec} / \mathrm{mm}^{2}$ and ADC mapping showing; mild restriction of the SI of the mural wall lesion, however the ADC value for the lesion measured $0.9 \times 10 \mathrm{~mm} / \mathrm{sec}$. Histo-pathologically, the tumor was confirmed as grade II invasive adenocarcinoma of the urinary bladder.

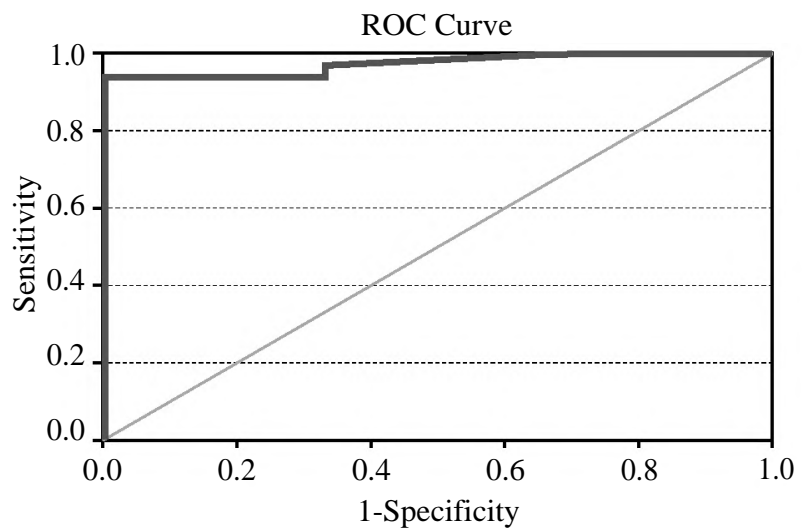

Fig. (3): ROC curve analysis to explore the discriminant ability of mean dADC value to differentiate high grade (Grade II \& III) from low grade (Grades I) tumors.

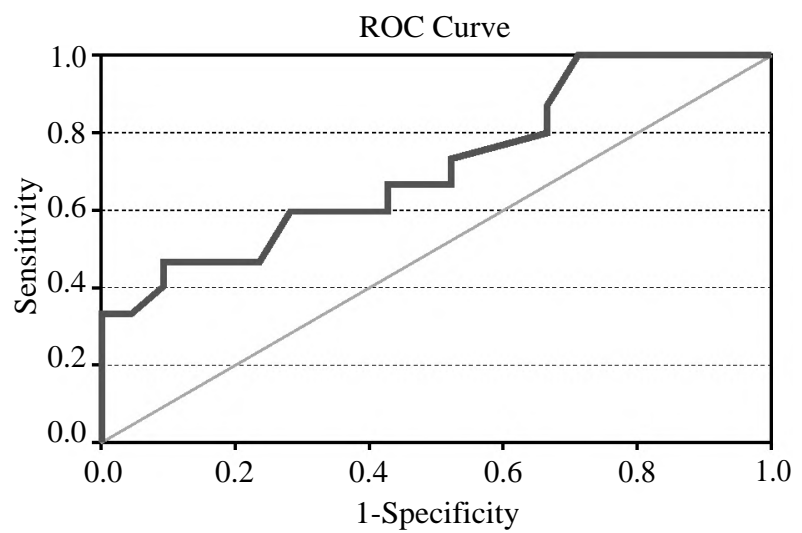

Fig. (4): ROC curve analysis to explore the discriminant ability of mean $\mathrm{dADC}$ value to differentiate high grade (Grade III) from low grade (Grades I \& II) tumors. 
Table (1): Description of study variables.

\begin{tabular}{ll}
\hline & Description $(\mathrm{n}=108)$ \\
\hline Age: & \\
Range & $17-79$ \\
Mean \pm SD & $60.81 \pm 12.24$ \\
Median (IQR) & $60.5(57.5-69)$ \\
Sex: & \\
Male & $81(75)$ \\
Female & $27(25)$ \\
Number of lesions: & \\
Single & $87(80.6)$ \\
Double & $15(13.9)$ \\
Multiple & $6(5.6)$ \\
Shape: & \\
Circumferential thickening & $60(55.6)$ \\
Exophytic mass & $18(16.7)$ \\
Endophytic mass & $21(19.4)$ \\
Mixed & $9(8.3)$ \\
Maximum thickness: & \\
<1 cm & $15(13.9)$ \\
1-3cm & $39(36.1)$ \\
>3 cm & $54(50)$ \\
Site: & \\
Diffuse & $45(41.7)$ \\
Dome & $21(19.4)$ \\
Anterior wall & $33(30.6)$ \\
Posterior wall & $45(41.7)$ \\
Right lateral wall & $39(36.1)$ \\
Left lateral wall & $24(22.2)$ \\
Inferior & $30(27.8)$ \\
\hline &
\end{tabular}

Table (2): Explore the discriminant ability of mean dADC value to differentiate high grade (Grade II \& III) from low grade (Grades I) tumors

\begin{tabular}{|c|c|c|c|c|c|c|c|c|}
\hline AUC & $\begin{array}{c}95 \% \\
\mathrm{CI}\end{array}$ & $\underset{\text { value }}{p^{-}}$ & $\begin{array}{l}\text { Cut- } \\
\text { off }\end{array}$ & Sen & Spec & PPV & NPV & Accuracy \\
\hline 0.975 & $\begin{array}{c}0.947 \\
1.000\end{array}$ & 0.000 & $\leq 0.91$ & $93.9 \%$ & $100 \%$ & $100 \%$ & $60 \%$ & $94.4 \%$ \\
\hline $\begin{array}{l}\text { AUC: } \\
\text { CI : } \\
\text { Sen. : }\end{array}$ & $\begin{array}{l}\text { Area L } \\
\text { Confid } \\
\text { Sensiti }\end{array}$ & $\begin{array}{l}\text { nder the } \\
\text { ence Int } \\
\text { vity. }\end{array}$ & $\begin{array}{l}\text { e Curve } \\
\text { terval. }\end{array}$ & $\begin{array}{l}\mathrm{Sp} \\
\mathrm{PP} \\
\mathrm{NF}\end{array}$ & $\begin{array}{l}\text { ec. }: \mathrm{Sp} \\
\mathrm{V}: \mathrm{Po} \\
\mathrm{V}: \mathrm{Ne}\end{array}$ & $\begin{array}{l}\text { cificity } \\
\text { itive } P \\
\text { gative } F\end{array}$ & $\begin{array}{l}\text { redicti } \\
\text { Predict }\end{array}$ & $\begin{array}{l}\text { ve Value. } \\
\text { ive Value. }\end{array}$ \\
\hline
\end{tabular}

Table (3): Explore the discriminant ability of mean dADC value to differentiate high grade (Grade III) from low grade (Grades I \& II) tumors.

\begin{tabular}{ccccccccc}
\hline AUC & $\begin{array}{c}95 \% \\
\text { CI }\end{array}$ & $\begin{array}{c}p^{-} \\
\text {value }\end{array}$ & $\begin{array}{c}\text { Cut- } \\
\text { off }\end{array}$ & Sen & Spec & PPV & NPV & Accuracy \\
\hline 0.714 & $\begin{array}{l}0.616- \\
0.813\end{array}$ & 0.000 & $\leq 0.77$ & $60 \%$ & $71.4 \%$ & $60 \%$ & $71.4 \%$ & $66.7 \%$ \\
\hline
\end{tabular}

\begin{tabular}{ll}
\hline AUC : Area Under the Curve. & Spec. : Specificity. \\
CI : Confidence Interval. & PPV : Positive Predictive Value. \\
Sen. : Sensitivity. & NPV : Negative Predictive Value.
\end{tabular}

\section{Discussion}

Urinary bladder cancer is one of the commenest urological malignancies, causing remarkable morbidity and mortality all over the world [7] clinico/ histo-pathological classification and staging of a tumor, are valuable information for the appropriate choice of the course of management which noticeably affects the tumor's final prognosis [8] .

DW-MRI is an extremely valuable imaging modality for the radiological assessment of the urinary bladder carcinoma, due to high tissue contrast, with absence of radiation exposure, multiplanar imaging capabilities, and short examination time; moreover there is no need for contrast media. Therefore it's incorporation in pre-operative assessment of urinary bladder tumors was reported in many studies. It also gives accurate information on cellular density, tissue compactness and membrane integrity by measuring the diffusion of water molecule in vivo, with lower loss of signal indicating low water diffusion and higher loss of signal indicating high water diffusion [9] .

In this study, we found that the mean ADC value of the studied urinary bladder lesions was $0.81 \pm 0.18 \times 10^{-3} \mathrm{~mm}^{2} / \mathrm{s}$.

This is similar to the mean ADC values reported by other previous studies; Kobayashi et al., [10] reported that the mean ADC value in their study was $0.86 \times 10^{-3} \mathrm{~mm} / \mathrm{s}$, while it was $0.88 \times 10_{2}$ $\mathrm{mm}^{2} / \mathrm{s}$ in Dagulli et al., [11] and $0.63 \times 10^{-3} \mathrm{~mm} / \mathrm{s}$ in Yoshida et al., study [12]

However; Lista et al., [2] and Li et al., [7] reported a slightly higher mean ADC value measuring $1.06 \times 10^{-5} \mathrm{~mm} / \mathrm{s}$ and $1.22 \pm 0.22 \times 10^{-3} \mathrm{~mm}^{2} / \mathrm{s}$, respectively.

In our study, $\mathrm{ADC}$ values ranged from 0.48 to $1.21 \times 10_{2}^{-3} \mathrm{~mm} / \mathrm{s}$, using the ADC value of 0.77 $\mathrm{X} 10^{-3} \mathrm{~mm} / \mathrm{s}$ as a cutoff value between high grade tumors (grades II \& III) and low grade tumors (grade I), has a sensitivity, specificity, PPV, NPV and accuracy of $60 \%, 71.4 \%, 60 \%, 71.4 \%$ and $66,7 \%$ respectively the mean ADC value of 0.91 X $10^{-3} \mathrm{~mm} / \mathrm{s}$ showed better statistical indices (sensitivity $93.7 \%$, specificity $100 \%$, PPV $100 \%$, NPV $60 \%$ and accuracy $94.4 \%$ ) and enhanced the performance of the ADC value in the assessment of the tumor celluarity of the bladder carcinoma.

And so, our result did not exceed the cut off value between low grade and high grade UB tumors set by previous studies, such as Wang et al., [13] who estimated a cutoff $\mathrm{ADC}_{-}$value, sensitivity and specificity of $0.899 \times 10^{-3} \mathrm{~mm}^{2} / \mathrm{sec}, 100 \%$, and $95 \%$, respectively.

Similarly Kobayashi et al., [10] study showed a cut off $\mathrm{ADC}_{-3}$ yalue, sensitivity and specificity $0.86 \times 10^{-3} \mathrm{~mm} / \mathrm{sec}, 88 \%$, and $85 \%$, respectively. 
This was consistent with Al Johi et al.,_[14] who stated that the ADC cutoff $<0.9 \times 10^{-3} \mathrm{~mm} / \mathrm{s}$ identified high-grade from low grade tumors with $91.7 \%$ sensitivity and $60 \%$ specificity.

The relation between the mean ADC value and the histological grade of the detected urinary bladder cancer was studied in the current work. We found that there was a significant inverse relation between them, meaning that tumors with higher grade (grade II \& and grade III) showed lower ADC values when compared with those of lower grade (grade I) $(p=0.000)$.

Our results showed the Mean ADC value for grade I tumors were $1.11 \pm 0.15 X_{-3} 10^{-3} \mathrm{~mm}^{2} / \mathrm{sec}$, of grade II were $0.83 \pm 0.14 \times 10_{-3}^{-3} \mathrm{~mm}_{2}^{2} / \mathrm{sec}$ and of grade III were $0.72 \pm 0.14 \times 10^{-3} \mathrm{~mm}^{2} / \mathrm{sec}$.

This is consistent with the previous studies of Wang et al., [13] , ${ }_{3}$ whom results were ADC of $\left(1.141 \pm 0.164 \times 10 \mathrm{~mm}_{-3} / \mathrm{sec}\right)$ for low grade tumors and $\left(0.766 \pm 0.091 \times 10^{-3} \mathrm{~mm} / \mathrm{sec}\right)$ for high grade tumors $(p<0.05)$.

We found a significant difference between the mean ADC value of tumors of grade I and III ( $p=$ $0.000)$; and between grade I and II $(p=0.000)$. However, there was less significant difference between grades II and III ( $p=0.022)$.

Going on the same path both Barsoum et al., [15], and Takeuchi et al., [16] found that the mean ADC value of grade I tumors was significantly higher than that of grade II and grade III tumors. They found the Mean ADC value for all grade III tumors was $<1.25 \times 10^{-3} \mathrm{~mm}^{2} / \mathrm{sec}$, and $<1.0 \times$ $10^{-3} \mathrm{~mm} / \mathrm{sec}$, respectively.

Unlikely was Yamada et al., [8], results which showed slightly higher than our study, the author found that the ADC value for the low grade tumors was $1.58 \pm 0.21 \times 10^{-3} \mathrm{~mm} / \mathrm{secand}_{-3}$ the high grade tumors was $\left(1.20 \pm 0.27 \times 10^{-3} \mathrm{~mm} / \mathrm{sec}\right)$ $(p<0.001)$.

This was different from the results of Al Johi et al., [14] who reported that significant difference in ADC values was found between grade I and grade III $(p<0.001)$, grade II and grade III $(p=$ $0.045)$ but not between grade I and grade II ( $p=$ $0.066)$. According to the WHO grading system (2004), high-grade tumors [No=84 (89.4\%)] showed significantly lower ADC than low-grade tumors $[\mathrm{No}=10(10.6 \%)](p=0.0460$, AUC: 0.74 , $95 \%$ confidence interval $=0.641-0.825)$.

\section{Conclusion:}

ADC value could be a good discriminator between low and high grade tumors and hence predictor of cancer cells that would respond to therapy

\section{References}

1- DOBRUCH J., DANESHMAND S., FISCH M., LOTAN Y., NOON A.P., RESNICK M.J., SHARIAT S.F., ZLOTTA A.R. and BOORJIAN S.A.: Gender and bladder cancer: A collaborative review of etiology, biology, and outcomes. European urology, Feb. 1, 69 (2): 300-10, 2016.

2- LISTA F., ANDRÉS G., CACERES F., De FATA F.R., RODRÍGUEZ-BARBERO J.M. and ANGULO J.C.: Evaluation of risk of muscle invasion, perivesical and/or lymph node affectation by diffusion-weighted magnetic nuclear resonance in the patient who is a candidate for radical cystectomy. Actas Urológicas Españolas (English Edition), Jul. 1; 37 (7): 419-24, 2013.

3- BALTZER P.A., BENNDORF M., DIETZEL M., GAJDA M., CAMARA O. and KAISER W.A.: Sensitivity and specificity of unenhanced MR mammography DWI combined with T2-weighted TSE imaging, ueMRM) for the differentiation of mass lesions. Eur. Radiol., 20 (5): 1101$10,2010$.

4- COSTANTINI M., BELLI P., RINALDI P., BUFI E., GIARDINA G., FRANCESCHINI G., et al.: Diffusionweighted imaging in breast cancer: Relationship between apparent diffusion coefficient and tumour aggressiveness. Clin. Radiol., 65 (12): 1005-12, 2010.

5- YOSHIDA S., TAKAHARA T., KWEE T.C., WASEDA Y., KOBAYASHI S. and FUJII Y.: DWI as an imaging biomarker for bladder cancer. American Journal of Roentgenology. Jun., 208 (6): 1218-28, 2017.

6- CHAN Y.H.: Biostatistics 102: Quantitative DataParametric \& amp; Non-parametric Tests. Singapore Med. J., 44 (8): 391-6, 2003.

7- LI H., LIU L., SHI Q., STEMMER A., ZENG H., LI Y. and ZHANG M.: Bladder cancer: Detection and image quality compared among iShim, RESOLVE, and ss-EPI diffusion-weighted MR imaging with high $b$ value at 3.0 T MRI. Medicine, Dec., 96 (50), 2017.

8- YAMADA Y., KOBAYASHI S., ISOSHIMA S., ARIMA K., SAKUMA H. and SUGIMURA Y.: The usefulness of diffusion-weighted magnetic resonance imaging in bladder cancer staging and functional analysis. Journal of cancer research and therapeutics, Oct. 1; 10 (4): 878, 2014.

9- ZHAI N., WANG Y.H., ZHU L.M., WANG J.H., SUN X.H., HU X.B., LI X., YU T., WANG X.L., MENG N. and YAN Q.C.: Sensitivity and specificity of diffusionweighted magnetic resonance imaging in diagnosis of bladder cancers. Clinical \& Investigative Medicine, Aug. 9; 38 (4): 173-84, 2015.

10- KOBAYASHI S., KOGA F., YOSHIDA S., MASUDA H., ISHII C., TANAKA H., KOMAI Y., YOKOYAMA M., SAITO K., FUJII Y. and KAWAKAMI S.: Diagnostic performance of diffusion-weighted magnetic resonance imaging in bladder cancer: Potential utility of apparent diffusion coefficient values as a biomarker to predict 
clinical aggressiveness. European radiology, Oct. 1;21 (10): 2178, 2011

11-DAGGÜLLI M., ONUR M.R., F1RDOLA S F., ONUR R., KOCAKOC E. and ORHAN I: Role of diffusion MRI and apparent diffusion coefficient measurement in the diagnosis, staging and pathological classification of bladder tumors. Urologiainternationalis, 87 (3): 346-52, 2011.

12- YOSHIDA S., KOGA F., KOBAYASHI S., et al.: Role of diffusion-weighted magnetic resonance imaging in predicting sensitivity to chemo radiotherapy in muscleinvasive bladder cancer. Int. J. Radiat. Oncol. Biol. Phys., 83: e21-e27, 2012.

13-WANG Y., LI Z., MENG X., HU X., SHEN Y., MORELLI J., LIN H., ZHANG Z. and HU D.: Non muscle-invasive and muscle-invasive urinary bladder cancer: Image quality and clinical value of reduced field-of-view versus con- ventional single-shot echo-planar imaging DWI. Medicine, Mar.; 95 b (10), 2016.

14- AL JOHI R. S., SEIFELDEIN G. S., MOEEN A.M., et al.: Diffusion weighted magnetic resonance imaging in bladder cancer, is it time to replace biopsy? Cent. European J. Urol., 71: 31-7, 2018.

15- BARSOUM N., TALAAT M. and SARAYA S.: Can diffusion-weighted MRI predict the histological grade of urinary bladder carcinoma? Kasr Al Ainy Medical Journal, May 1; 23 (2): 86, 2017.

16- TAKEUCHI M., SASAKI S., ITO M., OKADA S., TAKAHASHI S., KAWAI T., SUZUKI K., OSHIMA H., HARA M. and SHIBAMOTO Y.: Urinary bladder cancer: Diffusion-weighted MR imaging-accuracy for diagnosing T stage and estimating histologic grade. Radiology, Apr., 251 (1): 112-21, 2009.

\title{
دراسة إرتباطية بين قيمة ظاهرة معامل الإنتشار وتصنيف آنواع سرطان المثانه
}

\author{
المقدمة: تعتبر دراسة سرطان المثانة البولية ذات آهمية كبيرة لآنها واحدة من آكثر الآورام الخبيثة شيوعاً. التقييم الدقيق قبل الجراحة

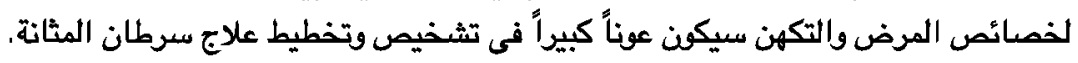 \\ الهدف من الدراسة: الهدف من هذه الدراسة هو ثقيّم دور قيمة معامل الإنتشار الظاهرى (ADC) في إكتشاف تصنيف سرطان المثانة \\ البولية قبل العلاج.

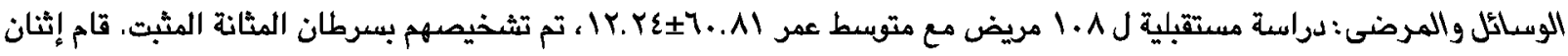

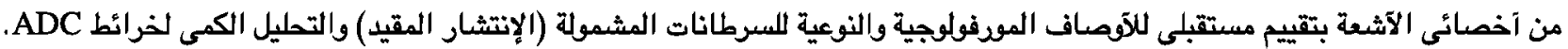 \\ تم حساب قيمة ADC المتوسطة لآفات المثانة وإرتبطت مع الدرجة المرضية التى تم تحديدها عن طريق خزعة إيرة مفتوحة آو آساسية (والتى \\ تعتبر مرجعاً قياسياً).

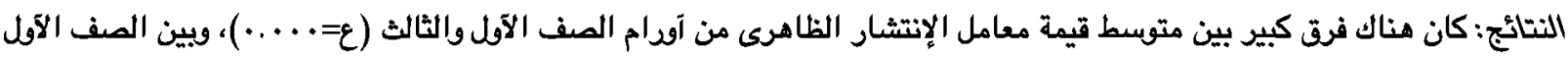

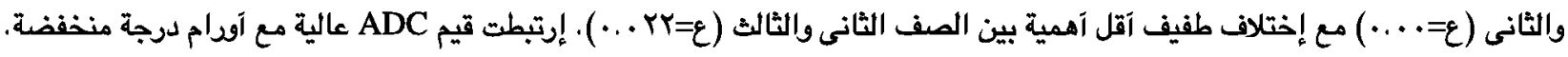 \\ الإستتاج: معامل الإنتشار الظاهرى هـ طريقة خالية من التباين تسمح بالتحليل الموفولوجى والكمى. تعد قيمة ADC تمييزاً جيداً بين

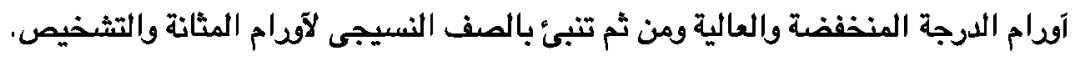

